\title{
Prevalence of chronic liver disease in patients with COVID-19 and their clinical outcomes: a systematic review and meta-analysis
}

\author{
Alexander J. Kovalic ${ }^{1}$ S Sanjaya K. Satapathy ${ }^{2}$ Paul J. Thuluvath ${ }^{3,4}$
}

Received: 6 June 2020 / Accepted: 18 July 2020 / Published online: 28 July 2020

(c) Asian Pacific Association for the Study of the Liver 2020

\begin{abstract}
Abnormal liver enzymes are seen in $20 \%$ of hospitalized patients with COVID-19. The etiology of elevated liver enzymes is thought to be multifactorial including medications and underlying liver disease. The true prevalence and clinical significance of underlying chronic liver diseases (CLD) in COVID-19 remains poorly defined. In this systematic review and meta-analysis, we included 74 clinical studies that were identified after a thorough literature search across three databases. The prevalence of CLD patients (73 studies, 24,299 patients) was 3\% among all COVID-19 patients. The prevalence of CLD patients was similar in COVID-19 positive and negative population (pooled OR 0.79 [95\% CI 0.60, 1.05], $p=0.10$ ). The presence of CLD was significantly associated with more severe COVID-19 infection (pooled OR 1.48 [95\% CI 1.17, 1.87], $p=0.001$ ) and overall mortality (pooled OR 1.78 [95\% CI 1.09, 2.93], $p=0.02$ ). Additionally, there was a non-significant trend noted for increased ICU admissions and need for invasive mechanical ventilation among COVID-19 patients with CLD. To date, the clinical importance of chronic liver diseases among COVID-19 infection has remained undefined. In this novel systematic review and meta-analysis, the presence of underlying chronic liver disease was significantly associated with more severe COVID-19 infections and mortality.
\end{abstract}

Keywords Liver · Cirrhosis · Chronic liver disease $\cdot$ Coronavirus · COVID-19 · Severe $\cdot$ Critical $\cdot$ ICU $\cdot$ Mechanical ventilation $\cdot$ Mortality

\section{Abbreviations}

ALD

CI

CLD Chronic liver disease

COVID-19 Novel coronavirus

$\mathrm{FiO} 2 \quad$ Inhaled oxygen concentration

Electronic supplementary material The online version of this article (https://doi.org/10.1007/s12072-020-10078-2) contains supplementary material, which is available to authorized users.

Paul J. Thuluvath

thuluvath@gmail.com

1 Department of Internal Medicine, Novant Forsyth Medical Center, Winston-Salem, NC, USA

2 Division of Hepatology, Department of Internal Medicine, Sandra Atlas Bass Center for Liver Diseases and Transplantation, Barbara and Zucker School of Medicine for Hofstra/Northwell Health, Manhasset, NY, USA

3 Institute of Digestive Health and Liver Diseases, Mercy Medical Center, Baltimore, MD, USA

4 Department of Medicine, University of Maryland School of Medicine, Baltimore, MD, USA

$\begin{array}{ll}\text { HBV } & \text { Hepatitis B virus } \\ \text { HCC } & \text { Hepatocellular carcinoma } \\ \text { HCV } & \text { Hepatitis C virus } \\ \text { ICU } & \text { Intensive care unit } \\ \text { NAFLD } & \text { Nonalcoholic fatty liver disease } \\ \text { OR } & \text { Odds ratio } \\ \text { PaO2 } & \text { Partial pressure arterial oxygen } \\ & \text { concentration } \\ \text { SpO2 } & \text { Oxygen saturation } \\ \text { WHO } & \text { World Health Organization }\end{array}$

\section{Introduction}

Abnormal liver enzymes (20\%) and elevated bilirubin $(16.7 \%)$ are common in hospitalized patients with COVID19 [1-3]. The etiology of abnormal liver enzymes is thought to be multifactorial, and in majority of patients, it is thought to be due to medications or underlying liver diseases [3].

It is not known whether patients with chronic liver disease (CLD) are more likely to develop COVID-19 as there is a paucity of data on the prevalence of CLD among patients 
with COVID-19. It has been suggested that chronic liver disease is an established risk factor for severe COVID-19 [4]. Although it is intuitive to believe that patients with cirrhosis, especially those with decompensated cirrhosis, are likely to have more severe COVID-19, there is no firm evidence to support this. In one study, only 19 of $5700(0.4 \%)$ of patients with COVID-19 hospitalized in NY hospitals had cirrhosis and only $11(0.2 \%)$ patients had either HCV or HBV [5]. Similarly, only 28 of 1591 (2\%) ICU admissions in Italy due to COVID-19 had chronic liver diseases. [6] The experience from Italy also suggests that COVID-19 is not disproportionately more common in liver transplant recipients, and 3 of 200 liver transplant recipients from one center who were tested positive did not develop pulmonary disease. [7] In another study from Milan, only 8 of 640 liver transplant recipients were diagnosed with COVID-19 during this pandemic, and of these only 5 were hospitalized and none required mechanical ventilation. [8] Moreover, there are only limited data on the clinical outcomes of patients with CLD including ICU admission, mechanical intubation rates, or mortality.

The primary aim of this systematic review and metaanalysis is to determine the prevalence of CLD in patients with COVID-19 and their clinical outcomes.

\section{Methods}

\section{Literature search}

Three major databases, including MEDLINE/PubMed, EMBASE, and medRxiv, were searched for clinical studies dated from January 1, 2019 to May 16, 2020. In an effort to broadly identify studies detailing CLD and COVID-19, the following search criteria were utilized: "(coronavirus OR Cov2 OR (Cov AND 2) OR ncov2 OR (ncov AND 2) OR (sars AND cov AND 2) OR (sars AND cov2) OR 'Sars Cov 2' OR COVID OR (covid AND 19) OR 'COVID 19') AND (chronic AND liver AND disease*) OR cirrhosis OR (hepatitis AND b) OR (hepatitis AND c) OR HBV OR HCV OR (alcohol AND liver AND disease) OR (alcoholic AND liver AND disease) OR ALD OR (nonalcoholic AND fatty AND liver) OR NAFLD OR (nonalcoholic AND steatohepatitis) OR (liver AND cancer) OR (hepatocellular AND carcinoma) OR HCC." This meta-analysis was conducted according to the Preferred Reporting Item for Systematic Reviews and Meta-Analyses [PRISMA] [9] and meta-analysis of observational studies and epidemiology [MOOSE] [10].

\section{Inclusion criteria}

Articles and clinical trials that met the following inclusion criteria were eligible for this meta-analysis: (1) studies performed in adult, human subjects; (2) studies reporting CLD among patients with COVID-19. No preference was given upon study design on the initial search strategy, and all types of studies including randomized controlled trials, non-randomized studies, cohort studies, and case-control studies were considered.

\section{Exclusion criteria}

Studies with the following characteristics were excluded from this meta-analysis: (1) studies performed among nonhuman subjects; (2) studies that were not a clinical trial, such as a review paper or letter; (3) studies that were out of scope of the study question detailed above; (4) studies that lacked proper controls; (5) studies that did not provide raw data in order to perform quantitative meta-analysis; (6) studies that were duplicates.

\section{Study definitions}

As mentioned above, CLD was defined by patients having any of the following diagnoses: cirrhosis, hepatitis B virus (HBV), hepatitis C virus (HCV), alcoholic liver disease (ALD), nonalcoholic fatty liver disease (NAFLD), or hepatocellular carcinoma (HCC).

Severe and critical COVID-19 infection was defined by criteria set forth in the WHO situation report and interim guidance [11]. Severe cases defined as any one of the following: respiratory distress with $\mathrm{RR}>30$ breaths per minute; mean oxygen saturation $\left[\mathrm{SpO}_{2}\right]<93 \%$ on room air; or arterial blood oxygen $\left[\mathrm{PaO}_{2}\right]$ /oxygen concentration $\left[\mathrm{FiO}_{2}\right] \leq 300 \mathrm{mmHg}$. Critical illness was defined by the presence of any one of the following: admission to ICU; respiratory failure requiring mechanical ventilation; shock; other multisystem organ failure requiring ICU level of care. Non-severe or mild cases of COVID-19 were defined as patients who tested positive for COVID-19, but did not meet criteria for severe or critical cases and were either asymptomatic or the symptoms from their infection were self-limiting.

\section{Statistical analysis}

This meta-analysis was performed using Review Manager [RevMan, software version 5.3, The Cochrane Collaboration, Denmark, 2014]. Odds Ratios [OR] were used as a summary measure for dichotomous data. $95 \%$ confidence intervals [CI] were reported for all measures. Data were considered statistically insignificant if OR includes 1.00 or $p>0.05$. Statistical heterogeneity was assessed using the $I^{2}$ statistic. $I^{2}$ values of $0-25 \%, 25-50 \%, 50-75 \%$, and $>75 \%$ 
were awarded values of homogeneity, mild heterogeneity, moderate heterogeneity, and high heterogeneity, respectively. If significant heterogeneity was present $\left[I^{2} \geq 50 \%\right]$, the random effects model was used to pool the effect sizes of included studies and subgroup analyses; if no significant heterogeneity was found $\left[I^{2}<50 \%\right]$, the fixed effects model was utilized. Publication bias was determined by visual inspection of funnel plots, which were calculated based on logarithmic ORs plotted against their standard errors [12]. Asymmetric funnel plots were deemed to represent studies with high risk of bias.

\section{Results}

\section{Study selection}

Overall, 437 clinical studies were identified for inclusion based upon the predefined search criteria. After a thorough literature appraisal and implementation of the exclusion criteria, 74 studies were finally included in this meta-analysis (Fig. 1 and Supplemental Table 2).

\section{Prevalence of CLD among patients with COVID-19}

Three studies (4221 patients) had compared the prevalence of CLD among COVID-19 positive patients and negative controls (Fig. 2). The prevalence of CLD patients was similar in COVID-19 positive and negative population with

Fig. 1 Study flow diagram

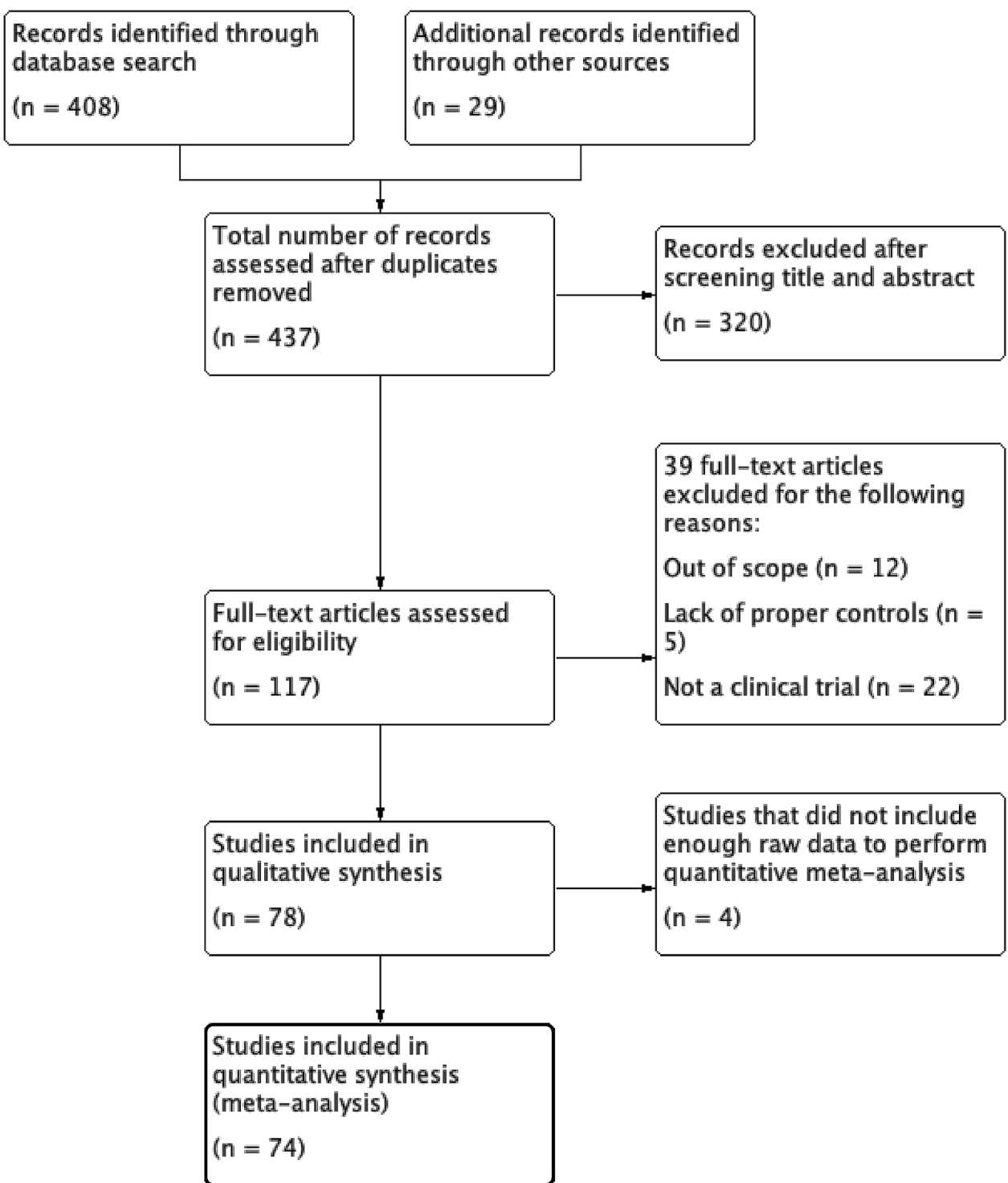




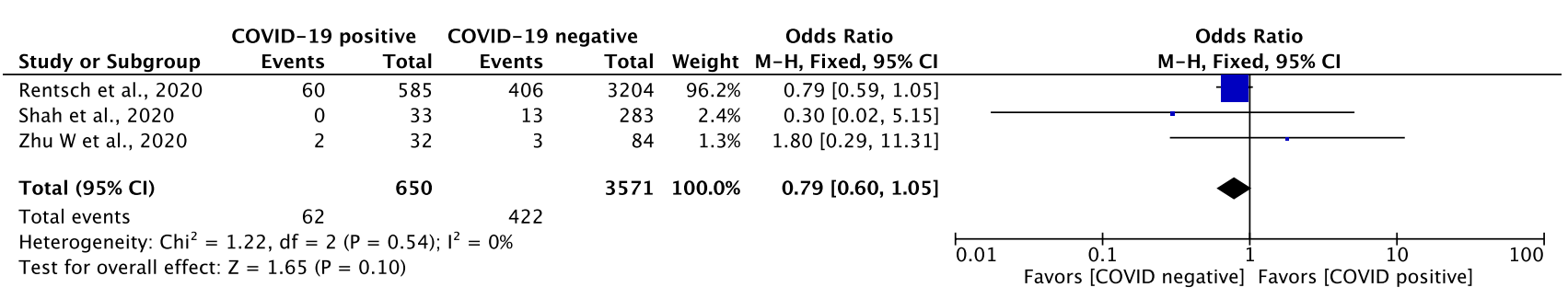

Fig. 2 Forest plot comparison of patients with underlying chronic liver disease among COVID-19 positive versus COVID-19 negative patients

pooled OR 0.79 [95\% CI $0.60,1.05 ; p=0.10 ; I^{2}=0 \%$ ]. In 73 studies (24,299 patients), the prevalence of CLD among patients positive for COVID-19 (regardless of the presence of negative controls) was 0.03 [95\% CI 0.03, 0.04] (Table 1).

\section{Clinical outcomes of patients with CLD and COVID-19}

Significantly greater severe and/or critical illness events were present among COVID-19 patients with CLD when compared to those without CLD (pooled OR 1.48 [95\% CI $1.17,1.87] ; p=0.001 ; \mathrm{I}^{2}=10 \%$ ) (Fig. 3). There were no significant differences in ICU admissions in COVID-19 patients with CLD when compared to patients without CLD (pooled OR 1.38 [95\% CI 0.88, 2.17]; $p=0.17 ; I^{2}=0 \%$ ), but there was a trend, and not statistically significant, towards increased rate of invasive mechanical ventilation among COVID-19 patients with CLD (pooled OR 2.22 [95\% CI $0.67,7.42] ; p=0.19 ; I^{2}=36 \%$ ) (Fig. 4). The overall mortality was significantly higher in COVID-19 patients with CLD when compared to COVID-19 patients without CLD (pooled OR 1.78 [95\% CI 1.09, 2.93]; $p=0.02 ; I^{2}=0 \%$ ) (Fig. 3).

\section{Publication bias}

Funnel plots were created for the outcomes of this metaanalysis and reported in Supplemental Figs. 1-3. No asymmetry was noted in the funnel plots to suggest a significant degree of publication bias.

\section{Discussion}

Our meta-analysis showed that there was no increased risk of COVID-19 in patients with CLD. However, patients with CLD were more likely to have severe or critical COVID-19 and they were also more likely to have a higher mortality when compared to those without CLD.

Recent recommendations made by the AASLD Expert Panel affirm an increased healthcare burden among COVID19 positive patients with CLD [13]. Although it is intuitive to believe that patients with CLD are likely to have more severe COVID-19, the above assumptions were made in the absence of robust clinical data and were largely based on expert opinion.

Previous two large studies outside China also appear to suggest that the prevalence of CLD is not higher in hospitalized patients $[5,6]$. Our meta-analysis supports those observations. Mild elevation of liver enzymes is common, especially in severe COVID-19, and it is thought to be multifactorial, and mostly medication related [1,3]. Our study provides important epidemiological information on the comparative prevalence of CLD in patients with and without COVID-19. After meticulously identifying studies among the primary literature, no significant difference was identified among the studies comparing the prevalence of CLD among patients with or without COVID-19. The overall prevalence of CLD was only $3 \%$ across all studies characterizing COVID-19 positive patients, and this is similar to the reported prevalence of CLD in hospitalized patients in New York and ICU patients in Italy [5, 6] Some studies from China had reported a higher prevalence mostly because of chronic hepatitis B in that population. It is very true that retrospective nature of most studies and the general lack of predefined diagnoses for CLD among studies may have underestimated the true prevalence of CLD in COVID-19.

Our study, however, showed that those with CLD are more likely to have more severe or critical COVID-19 illness when compared to those without CLD, and moreover, those with CLD are more likely to have a higher mortality. An EMR based, propensity matched, study had recently reported higher mortality in 250 patients with CLD and our findings corroborate it [14]. Moreover, meta-analyses of early data, one based on 11 observational studies [15] and another one based on 22 studies [16], had also come to similar conclusions. We can only speculate that some of these observations could be related to decompensation precipitated by COVID-19 in those with advanced cirrhosis or perhaps related other comorbidities in the population with liver disease. We need more granular data to make any firm conclusions. Our data have also demonstrated a trend towards an increased frequency of ICU admissions and requirement for invasive mechanical ventilation. Previous studies had reported higher prevalence of liver injury in 
Table 1 Prevalence of chronic liver diseases among COVID-19 positive patients

\begin{tabular}{|c|c|c|c|c|}
\hline Study & Country & $\begin{array}{l}\text { COVID-19 positive } \\
\text { patients with CLD }\end{array}$ & $\begin{array}{l}\text { Total COVID positive } \\
\text { patients }\end{array}$ & $\begin{array}{l}\text { CLD prevalence among } \\
\text { COVID-19 positive patients } \\
{[95 \% \mathrm{CI}]}\end{array}$ \\
\hline Ren et al. (2020) & China & 1 & 5 & $0.20[-0.15,0.55]$ \\
\hline Kujawski et al. (2020) & USA & 2 & 12 & $0.17[-0.04,0.38]$ \\
\hline Chen et al. (2020) & China & 15 & 123 & $0.12[0.06,0.18]$ \\
\hline Chen et al. (2020) & China & 3 & 25 & $0.12[-0.01,0.25]$ \\
\hline Xu et al. (2020) & China & 7 & 62 & $0.11[0.03,0.19]$ \\
\hline Rentsch et al. (2020) & USA & 60 & 585 & $0.10[0.08,0.13]$ \\
\hline Yanover et al. (2020 & Israel & 404 & 4353 & $0.09[0.09,0.10]$ \\
\hline Shi et al. (2020) & China & 7 & 81 & $0.09[0.03,0.15]$ \\
\hline Chen et al. (2020) & China & 4 & 48 & $0.08[0.00,0.16]$ \\
\hline Zhu et al. (2020) & China & 21 & 325 & $0.07[0.04,0.09]$ \\
\hline Li et al. (2020) & China & 6 & 85 & $0.07[0.02,0.13]$ \\
\hline Yu et al. (2020) & China & 2 & 28 & $0.07[-0.03,0.17]$ \\
\hline Zha et al. (2020) & China & 2 & 31 & $0.07[-0.02,0.15]$ \\
\hline Luo et al. (2020) & China & 25 & 403 & $0.06[0.04,0.09]$ \\
\hline Zhang et al. (2020) & China & 8 & 140 & $0.06[0.02,0.10]$ \\
\hline Du et al. (2020) & China & 5 & 85 & $0.06[0.01,0.11]$ \\
\hline Ji et al. (2020) & China & 6 & 101 & $0.06[0.01,0.11]$ \\
\hline Liu et al. (2020) & China & 5 & 89 & $0.06[0.01,0.10]$ \\
\hline Song et al. (2020) & China & 4 & 73 & $0.06[0.00,0.11]$ \\
\hline Li et al. (2020) & China & 1 & 17 & $0.06[-0.05,0.17]$ \\
\hline Zhu et al. (2020) & China & 2 & 32 & $0.06[-0.02,0.15]$ \\
\hline Sun et al. (2020) & China & 3 & 55 & $0.06[-0.01,0.12]$ \\
\hline Chen et al. (2020) & China & 15 & 291 & $0.05[0.03,0.08]$ \\
\hline Wang et al. (2020) & China & 12 & 242 & $0.05[0.02,0.08]$ \\
\hline Zhao et al. (2020 & China & 4 & 75 & $0.05[0.00,0.10]$ \\
\hline Arentz et al. (2020 & USA & 1 & 21 & $0.05[-0.04,0.14]$ \\
\hline Liu et al. (2020) & China & 2 & 41 & $0.05[-0.02,0.12]$ \\
\hline Fu et al. (2020) & China & 9 & 200 & $0.04[0.02,0.07]$ \\
\hline Lian et al. (2020) & China & 31 & 819 & $0.04[0.02,0.05]$ \\
\hline Lu et al. (2020) & China & 20 & 577 & $0.04[0.02,0.05]$ \\
\hline Mo et al. (2020) & China & 7 & 155 & $0.04[0.01,0.08]$ \\
\hline Shi et al. (2020) & China & 5 & 134 & $0.04[0.01,0.07]$ \\
\hline Wu et al. (2020) & China & 7 & 201 & $0.04[0.01,0.06]$ \\
\hline Yan et al. (2020) & China & 6 & 168 & $0.04[0.01,0.06]$ \\
\hline Feng et al. (2020) & China & 4 & 114 & $0.04[0.00,0.07]$ \\
\hline Wang et al. (2020) & China & 3 & 69 & $0.04[-0.01,0.09]$ \\
\hline Chen et al. (2020) & China & 2 & 57 & $0.04[-0.01,0.08]$ \\
\hline Zhang et al. (2020) & China & 7 & 221 & $0.03[0.01,0.06]$ \\
\hline Cao et al. (2020) & China & 6 & 198 & $0.03[0.01,0.05]$ \\
\hline Huang et al. (2020 & China & 6 & 221 & $0.03[0.01,0.05]$ \\
\hline Regina et al. (2020 & Switzerland & 6 & 200 & $0.03[0.01,0.05]$ \\
\hline Zhang et al. (2020 & China & 9 & 315 & $0.03[0.01,0.05]$ \\
\hline Cai et al. (2020 & China & 8 & 298 & $0.03[0.01,0.04]$ \\
\hline Wang et al. (2020 & China & 4 & 138 & $0.03[0.00,0.06]$ \\
\hline Liu et al. (2020 & China & 1 & 32 & $0.03[-0.03,0.09]$ \\
\hline Su et al. (2020) & China & 2 & 73 & $0.03[-0.01,0.06]$ \\
\hline Guan et al. (2020) & China & 23 & 1099 & $0.02[0.01,0.03]$ \\
\hline Bai et al. (2020) & China & 3 & 127 & $0.02[0.00,0.05]$ \\
\hline
\end{tabular}


Table 1 (continued)

\begin{tabular}{|c|c|c|c|c|}
\hline Study & Country & $\begin{array}{l}\text { COVID-19 positive } \\
\text { patients with CLD }\end{array}$ & $\begin{array}{l}\text { Total COVID positive } \\
\text { patients }\end{array}$ & $\begin{array}{l}\text { CLD prevalence among } \\
\text { COVID-19 positive patients } \\
{[95 \% \mathrm{CI}]}\end{array}$ \\
\hline Du et al. (2020) & China & 4 & 179 & $0.02[0.00,0.04]$ \\
\hline Xiao et al. (2020) & China & 4 & 197 & $0.02[0.00,0.04]$ \\
\hline Huang et al. (2020) & China & 1 & 41 & $0.02[-0.02,0.07]$ \\
\hline Liu et al. (2020) & China & 1 & 51 & $0.02[-0.02,0.06]$ \\
\hline Song et al. (2020) & China & 1 & 51 & $0.02[-0.02,0.06]$ \\
\hline Yang et al. (2020) & China & 1 & 55 & $0.02[-0.02,0.05]$ \\
\hline Cao et al. (2020) & China & 2 & 102 & $0.02[-0.01,0.05]$ \\
\hline Duan et al. (2020) & China & 2 & 116 & $0.02[-0.01,0.04]$ \\
\hline Liu et al. (2020) & China & 2 & 112 & $0.02[-0.01,0.04]$ \\
\hline Yao et al. (2020) & China & 2 & 108 & $0.02[-0.01,0.04]$ \\
\hline Wan et al. (2020) & China & 2 & 135 & $0.01[0.00,0.03]$ \\
\hline Qin et al. (2020) & China & 6 & 452 & $0.01[0.00,0.02]$ \\
\hline Almazeedi et al. (2020) & Kuwait & 6 & 1099 & $0.01[0.00,0.01]$ \\
\hline Liu et al. (2020) & China & 3 & 620 & $0.01[0.00,0.01]$ \\
\hline Richardson et al. (2020) & USA & 30 & 5700 & $0.01[0.00,0.01]$ \\
\hline Wang et al. (2020) & China & 2 & 339 & $0.01[0.00,0.01]$ \\
\hline Yan et al. (2020) & China & 1 & 192 & $0.01[0.00,0.01]$ \\
\hline Liu et al. (2020) & China & 1 & 80 & $0.01[-0.01,0.04]$ \\
\hline Wang et al. (2020) & China & 1 & 69 & $0.01[-0.01,0.04]$ \\
\hline Wu et al. (2020) & China & 1 & 80 & $0.01[-0.01,0.04]$ \\
\hline Wang et al. (2020) & China & 2 & 165 & $0.01[-0.01,0.03]$ \\
\hline Zhang et al. (2020) & China & 1 & 111 & $0.01[-0.01,0.03]$ \\
\hline Guo et al. (2020) & China & 1 & 118 & $0.01[-0.01,0.02]$ \\
\hline Shabrawishi et al. (2020) & Saudi Arabia & 1 & 150 & $0.01[-0.01,0.02]$ \\
\hline Lu et al. (2020) & China & 1 & 265 & $0.00[0.00,0.01]$ \\
\hline Total & & 875 & 23,424 & $0.03[0.03,0.04]$ \\
\hline
\end{tabular}

those with severe COVID-19 and this could be major confounder of mortality in patients with CLD [2].

Despite the novel findings presented, in addition to minimal heterogeneity across studies, this systematic review and meta-analyses have some limitations. Most of the included studies were retrospective and based on hospitalized patients. These studies also may have under-reported CLD among comorbidities since CLD was not the primary focus of their studies and moreover, there was no predefined definition for CLD in these studies. In addition, the majority of studies did not stratify CLD patients based on the etiology of CLD, and most studies were from China, where chronic hepatitis B is more prevalent. In spite of the above limitations, this systematic review and metaanalysis provides useful information on the prevalence and complication of COVID-19 infection in those with CLD, and highlights the importance of prospective casecontrolled studies that include both outpatients and hospitalized patients. 


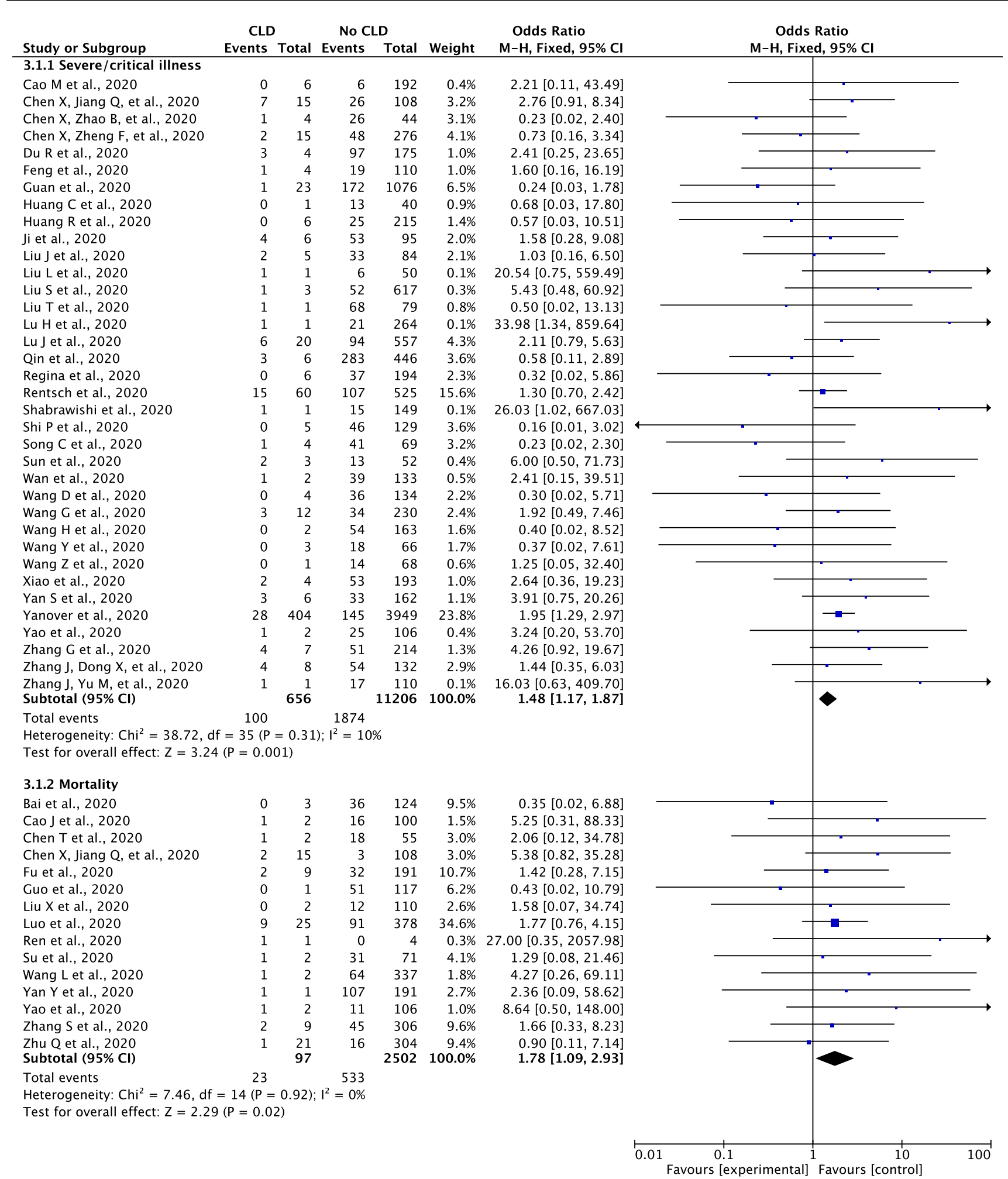

Fig. 3 Forest plot comparison of severity of illness [3.1.1] and mortality [3.1.2] among COVID-19 positive patients with versus without chronic liver diseases 


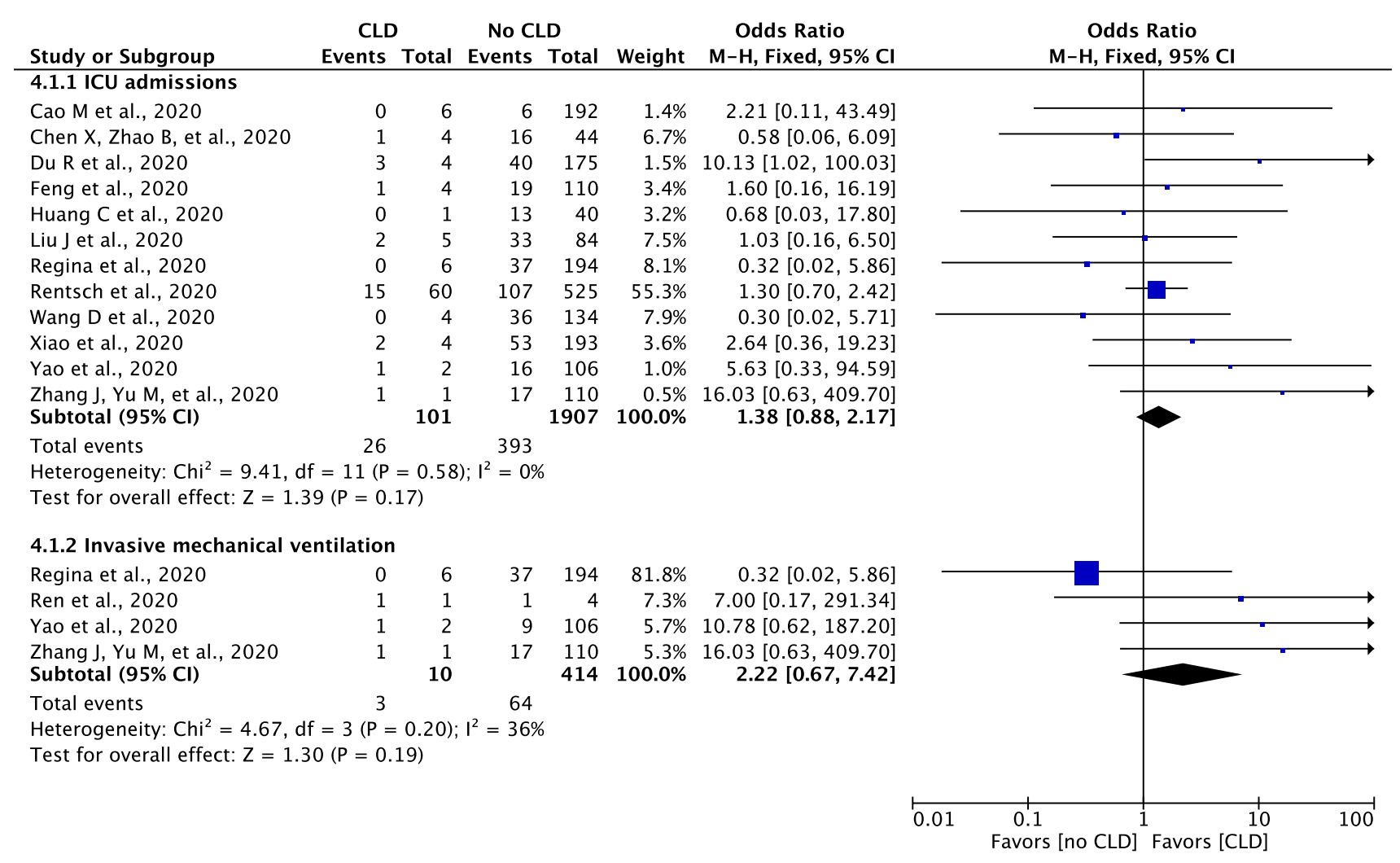

Fig. 4 Forest plot comparison of ICU admissions [4.1.1] and rates of invasive mechanical ventilation [4.1.2] among COVID-19 positive patients with versus without chronic liver diseases

\begin{abstract}
Author contributions AK provided substantial contributions to conception and design of the study, acquisition of data/analysis and interpretation of data, drafting of the article, critical revisions of the article, and final approval of article. SS and PT provided substantial contributions to conception and design of the study, critical revisions of the article, and final approval of article
\end{abstract}

Funding This systematic review and meta-analysis did not receive funding of any kind.

\section{Compliance with ethical standards}

Conflict of interest Alexander J. Kovalic, Sanjaya K. Satapathy and Paul J. Thuluvath authors have no conflict of interest to disclose in the writing of this manuscript.

\section{References}

1. Sultan S, Altayar O, Siddique SM, Davitkov P, Feuerstein JD, Lim JK, Falck-Ytter Y, et al. 7 on behalf of the AGA. AGA institute rapid review of the GI and liver manifestations of COVID-19, meta analysis of international data, and recommendations for the consultative management of patients with COVID-19. Gastroenterology. 2020. https://doi.org/10.1053/j.gastro.2020.05.001.

2. Cai Q, Huang D, Yu H, Zhu Z, Xia Z, Su Y, Li Z, et al. COVID19: abnormal liver function tests. J Hepatol. 2020. https://doi. org/10.1016/j.jhep.2020.04.006.
3. Mao R, Liang J, Shen J, Ghosh S, Zhu LR, Yang H, Wu KH, et al. On behalf og Chinese Society of IBD. Implications of COVID-19 for patients with pre-existing digestive diseases. Lancet Gastroenterol Hepatol. 2020;5(5):425-7. https://doi.org/10.1016/S2468 -1253(20)30076-5.

4. Gandhi RT, Lynch JB, Del Rio C. Mild or moderate covid-19. N Engl J Med. 2020. https://doi.org/10.1056/NEJMcp2009249.

5. Richardson S, Hirsch JS, Narasimhan M, et al. Presenting characteristics, comorbidities, and outcomes among 5700 patients hospitalized With COVID-19 in the New York city area. JAMA. 2020. https://doi.org/10.1001/jama.2020.6775.

6. Grasselli G, Zangrillo A, Zanella A, et al. For the COVID-19 lombardy ICU network baseline characteristics and outcomes of 1591 patients infected with SARS-CoV-2 admitted to ICUs of the Lombardy Region, Italy. JAMA. 2020. https://doi.org/10.1001/ jama.2020.5394.

7. D'Antiga L. Coronaviruses and immunosuppressed patients: the facts during the third epidemic. Liver Transpl. 2020. https://doi. org/10.1002/lt.25756.

8. Donato MF, Invernizzi F, Lampertico P, Rossi G. Health status of liver transplant patients during the coronavirus outbreak in Italy: a large single center experience from Milan. Clin Gastroenterol Hepatol. 2020. https://doi.org/10.1016/j.cgh.2020.04.041.

9. Moher D, Liberati A, Tetzlaff J, et al. Preferred reporting items for systematic reviews and meta-analyses: the PRISMA statement. Ann Intern Med. 2009;151(264-9):w64.

10. Stroup DF, Berlin JA, Morton SC, et al. Meta-analysis of observational studies in epidemiology: a proposal for reporting. Metaanalysis Of Observational Studies in Epidemiology (MOOSE) group. JAMA. 2000;283:2008-122. 
11. Clinical management of Covid-19. Interim Guidance 27 May 2020. WHO reference number WHO/2019-nCoV/clinical/2020.5. https://www.who.int/publications/i/item/clinical-management-ofcovid-19.

12. Easterbrook PJ, Berlin JA, Gopalan R, et al. Publication bias in clinical research. Lancet. 1991;337:867-72.

13. Fix OK, Hameed B, Fontana RJ, Kwok RM, McGuire BM, Mulligan DC, Pratt DS, et al. Clinical best practice advice for hepatology and liver transplant providers during the COVID-19 Pandemic: AASLD expert panel consensus statement. Hepatology. 2020. https://doi.org/10.1002/hep.31281.

14. Singh S, Khan A. Clinical characteristics and outcomes of COVID-19 among patients with preexisting liver disease in united states: a multi-center research network study. Gastroenterology. 2020. https://doi.org/10.1053/j.gastro.2020.04.064.

15. Mantovani A, Beatrice G, Dalbeni A. Coronavirus disease 2019 and prevalence of chronic liver disease: a meta-analysis. Liver Int. 2020;40:1316-20.

16. Oyelade T, Alqahtani J, Canciani G. Prognosis of COVID-19 in Patients with liver and kidney diseases: an early systematic review and meta-analysis. Trop. Med. Infect. Dis. 2020;5:80. https://doi. org/10.3390/tropicalmed5020080.

Publisher's Note Springer Nature remains neutral with regard to jurisdictional claims in published maps and institutional affiliations. 